\title{
Patterning of cells in the Drosophila eye by Lozenge, which shares homologous domains with AML1
}

\author{
Andrea Daga, ${ }^{1}$ Chris A. Karlovich,, ${ }^{1}$ Karin Dumstrei, and Utpal Baneriee \\ Department of Molecular, Cell and Developmental Biology, Molecular Biology Institute; and Brain Research Institute, \\ University of California, Los Angeles, California 90095 USA
}

\begin{abstract}
The lozenge $(l z)$ gene encodes a transcription factor involved in prepatterning photoreceptor precursors in the developing Drosophila eye. The central region of the predicted Lz protein product is homologous to AML1, a transcription factor associated with human leukemias, and to the Drosophila protein Runt. We show here that $\mathrm{Lz}$ plays a crucial role in governing the fate of two groups of cells that are born in a single round of mitosis in the larval eye disc. Lz helps define a subset of these cells as an equipotential group that is competent to respond to the Sevenless developmental signal. This is achieved by negative regulation of seven-up, a member of the steroid hormone receptor superfamily in these cells. In contrast, in a second group of cells, the $\mathrm{Lz}$ protein confers proper photoreceptor identity by positively regulating the homeo box gene Bar. Additionally, our genetic analysis suggests that $\mathrm{Lz}$ interacts with the Ras pathway to determine photoreceptor cell fate. This study suggests that the strategies involved in cell fate determination in the Drosophila eye are remarkably similar to those utilized during vertebrate hematopoietic development and require the coordinate action of growth factor and AML1-like pathways.
\end{abstract}

[Key Words: PEBP2 $\alpha$; Runt; neuronal differentiation; Drosophila; AMLl; eye development; Seven-up; Bar]

Received March 6, 1996; revised version accepted April 11, 1996.

The generation of diversity within a homogeneous population of cells involves two important processes. First, a subset of cells belonging to a single equivalence group competent to respond identically to a given developmental signal is created within a population of undifferentiated cells. Second, a signal is sent to one or more members of this group, allowing them to adopt a fate that is different from that of their neighbors. For example, in the development of the Caenorhabditis elegans vulva, six cells are set aside as an equivalence group, with only one becoming the primary vulval precursor cell, and in each ommatidium of the Drosophila compound eye, the R7 and cone cell precursors are competent to become R7 in response to the Sevenless (Sev) signal (for review, see Greenwald and Rubin 1992). Therefore, these cells possess equivalent developmental potential and belong to a single equivalence group called the R7 equivalence group (Dickson et al. 1992). In both of these systems, much is known about the nature of the signals that initiate cellfate determination, but the molecular mechanism for generating the equivalence groups is not as well understood.

The Drosophila eye develops from an epithelial structure called the eye imaginal disc in the third larval instar. The appearance of a morphogenetic furrow, an in-

${ }^{1}$ These two authors contributed equally to this paper. dentation in the disc epithelium that progresses from posterior to anterior, marks the onset of cell differentiation and pattern formation (for review, see Heberlein and Moses 1995). Cells anterior to the furrow are undetermined, whereas cells immediately posterior initiate ommatidial assembly by adopting distinct neuronal identities. In the adult fly, these cells will become photoreceptors R1-R8. The first cell to differentiate within a developing cluster is the R8 precursor, followed by the pairwise differentiation of R2/R5 and R3/R4. Cells that do not join the precluster all undergo a synchronized round of cell division, and the precursors of R1/R6, R7, and cone cells arise from this second round of cell division completing the assembly of the adult ommatidium (Tomlinson and Ready 1987a).

The determination of cell fate within an ommatidium is not dictated by lineage (Ready et al. 1976); rather, different cell types have been proposed to develop in response to a spatially and temporally restricted sequence of inductive interactions between multipotent precursors (Tomlinson and Ready 1987b). The most understood example of such an interaction involves the differentiating R8 cell and the presumptive R7 cell, resulting in the latter adopting a neuronal fate (for review, see Zipursky and Rubin 1994). This process is triggered by the activation of the Sev receptor tyrosine kinase (RTK) on the surface of the R7 precursor by its ligand, Bride of Sev- 
enless Boss, localized to the R8 cell membrane (Krämer et al. 1991). The signal thus generated causes the activation of Ras (Simon et al. 1991) and a kinase cascade, involving Raf, MEK, and MAP kinase, ensues (for review, see Zipursky and Rubin 1994). The activation of MAP kinase ultimately leads to the phosphorylation of nuclear factors, such as Yan and Pointed within the R7 precursor (Brunner et al. 1994; Rebay and Rubin 1995).

Although Sev is required exclusively for the development of R7, this protein is also expressed at high levels in the R3/R4 and cone cell precursors, and weakly in R1 and R6 (Tomlinson et al. 1987). In spite of the direct apposition of the Sev-expressing photoreceptor precursors with the Boss-expressing R8, these cells do not initiate an R7 developmental fate. Moreover, whereas ectopic expression of activated Sev in cone cells causes them to differentiate as $R 7$, expression in the presumptive R3/R4 and R1/R6 does not alter their differentiation as outer photoreceptors (Basler et al. 1991). These latter cells seem to be excluded from the R7 equivalence group because they are the only cells to express Seven-up (Svp) a member of the steroid hormone receptor superfamily (Mlodzik et al. 1990). svp mutations are recessive lethal, and in homozygous mutant clones of the adult eye, R3/ $\mathrm{R} 4$ and R1/R6 are transformed to an R7 fate. Targeted misexpression of $s v p$ in cone and $\mathrm{R} 7$ precursors has shown that low doses of ectopic Svp will cause cone cells to be converted into R7 photoreceptors, whereas righ levels will cause both the $\mathrm{R} 7$ and cone cell precursors to adopt an outer photoreceptor identity (Hiromi et al. 1993; Begemann et al. 1995; Kramer et al. 1995). Although svp mutations cause an outer photoreceptor to $\mathrm{R} 7$ conversion, Svp is not a negative regulator of $\mathrm{R} 7 \mathrm{de}$ velopment per se. Rather, the misexpression studies described above suggest that it is a positive regulator of neuronal fate. It seems clear that the tightly regulated expression of Svp is essential for the proper assembly of cells within an ommatidium.

To carry out their differentiation program properly, in addition to Svp, photoreceptors R1/R6 require the product of the gene Bar (Higashijima et al. 1992), a homeo domain protein whose expression is restricted exclusively to R1/R6. Thus, the coordinate control of the expression of Svp and Bar is important in the specification of equivalence groups of cells. A more detailed understanding of the mechanisms that control the spatial distribution of these transcription factors should provide new insights as to how equivalence groups are defined within the developing ommatidium. Because the mechanisms underlying pattern formation seem to be fairly universal, this could also provide information that will be applicable to patterning of cells in vertebrate systems.

Previous studies have suggested that signals such as those generated by Sev are triggers (Basler et al. 1990) that allow preprogrammed cells to carry out the developmental steps that they are competent for. Although the Sev pathway has been instrumental in the identification of an important signal transduction cascade, to determine the molecular basis for patterning in the eye, it is important to identify genes that control the cell- specific expression of transcription factors such as Svp, Bar, Rough (Tomlinson et al. 1988), and Atonal (Jarman et al. 1994). Here, we report the isolation and molecular characterization of lozenge $\{l z\}$, a gene that, by controlling Svp and Bar expression in the developing eye disc, helps define the fate of the cells that arise from the second wave of mitotic division (R1/R6, R7, and cone cells).

\section{Results}

\section{Sprite mimics svp}

A mutant displaying a dominant phenotype characterized by the conversion of outer photoreceptor neurons R3 and R4 to central R7-like photoreceptors (Fig. 1B), was isolated as a P-element insertion in the $8 \mathrm{D} / \mathrm{E}$ region of the $\mathrm{X}$ chromosome. The P-element vector used contained two tandem copies of the sev enhancer (sE) element, which directs expression of genes under its control strongly in cells that nomally express Sev. The phenotype of this mutant is reminiscent of the conversion of R3 and R4 to R7 seen in loss-of-function mutations in svp; thus, we named this mutant Sprite. As will be shown later, Sprite represents a gain-of-function allele of the $l z$ locus, which we shall henceforth refer to as $l z^{\text {sprite }}$.

The $1 z^{\text {sprite }}$ mutation is viable and the change in R3 ${ }^{-\lambda} \mathrm{R} 4$ to an $\mathrm{R} 7$ cell fate can be scored in adult eyes. The $1 z^{i n n t e}$ mutant phenotype is partially penetrant and dosage-dependent (Fig. $1 \mathrm{H}$ ). In $\mathrm{Iz}^{\text {Sprite }} /+$ flies, $72 \%$ of the ommatidia show transformation of R4 into an R7 cell, and in $10 \%$ of the ommatidia, both R3 and R4 become converted. This shows that the $\mathrm{R} 4$ precursor cell is more sensitive to the dosage of $1 z^{\text {Sprite }}$ than the R3 precursor in acquiring an R7 identity. The phenotype is more extreme in $1 z^{\text {Sprite }} / 1 z^{\text {Sprite }}$ flies. No wild-type facets are seen, and double conversions are observed in $73 \%$ of the ommatidia. In addition, $5 \%$ of $1 z^{\text {Sprite }}$ ommatidia lack one outer cell.

Because $s v p$ is required in R3 and R4 for correct cell fate specification, we utilized the $s v p-l a c Z$ enhancer trap line AE127 (Fischer-Vize et al. 1992) to determine whether the $1 z^{\text {Sprite }}$ mutant phenotype is attributable to an altered expression of Svp. In wild-type third-instar eye discs, during the five-cell precluster stage, the two cells that will become R3 and R4 express $s v p-l a c Z$, and subsequently, at the 8-cell stage, R1 and R6 also turn on Svp expression (Fig. 1F). When the $s v p$-lac $Z$ line is crossed into a $1 z^{\text {Sprite }}$ background only two cells per cluster, R1 and R6, have detectable levels of lacZ expression (Fig. $1 G)$. Thus, the developmental basis for the cell fate conversion in $l z^{\text {Sprite }}$ is an absence of $s v p$ expression in the $\mathrm{R} 3$ and R4 precursors.

To test whether the converted R7-like cells in $1 z^{\text {sprite }}$ are dependent on signaling through Sev, we recombined the null allele, $\mathrm{sev}^{d 2}$, onto the $1 z^{\text {sprite }}$ chromosome. In a $s e v^{d 2}$ background, the $\mathrm{R} 7$ precursor never develops into a mature R7 cell; therefore, any R7-like cells seen in this background can be assumed to have arisen by conversion from outer cells. In $1 z^{\text {Sprite }}$ eyes, an average of 1.7 $\{n=1821)$ converted central cells are seen per ommatid- 
Daga et al.
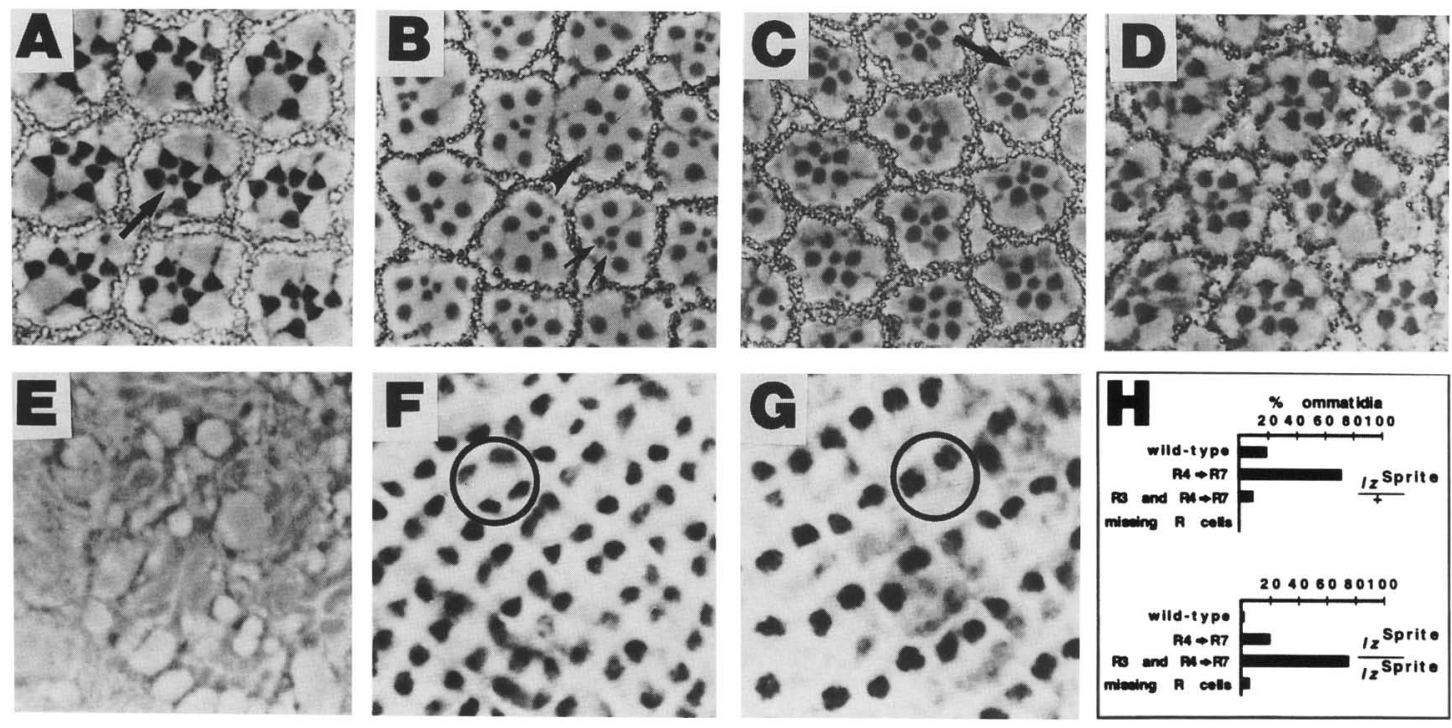

Figure 1. Phenotypic analysis of $l z^{\text {sprite }} .|A-E|$ Tangential sections of adult eyes. $|A|$ Wild type. The dark, trapezoidally arranged structures within each ommatidium are membrane specializations (rhabdomeres) of the photoreceptor cells. R1-R6 have large rhabdomeres, whereas the smaller, centrally positioned rhabdomere belongs to R7 (arrow). R8 is not seen in this plane of section. Pigment cells are positioned hexagonally along the ommatidial boundaries. $|B| l z^{\text {sprite }} / \mathrm{Y}$. R3 and R4 are transformed into R7-like cells $\mid$ arrows $\mid$ in a majority of the ommatidia. An ommatidium in which R4 but not R3 is converted into R7 is marked with an arrowhead. Ommatidia in which R3 alone is converted are never seen. $\left(\mathrm{Cl} \mathrm{sev} d 2, l z^{\mathrm{sprtt}} / \mathrm{Y}\right.$. In a sev $\mathrm{v}^{d 2}$ background, many of the converted R7 cells fail to develop as photoreceptor neurons, but about one-third of them (arrow) can still be seen. This suggests that the converted R7 cells are partially dependent on Sev. $(D) \mathrm{sE}[\mathrm{c} 3.5]$. Transgenic flies in which c3.5 is expressed under the control of the sev enhancer display a transformation of R3 and R4 cell types into R7, much as is seen in $l z^{\text {sprite }} .|E| l z^{r 1} / \mathrm{Y}$. These eyes are severely affected, with the photoreceptor and pigment cell lattice completely disrupted. $|F, G|$ Eye imaginal discs stained with an antibody against $\beta$-galactosidase. $(F)$ svp-lac $Z$ enhancer-trap line AE127. In this enhancer trap line, the expression of $\beta$-galactosidase resembles that of the $s v p$ gene. In each cluster (one circled for clarity), R3/R4 and Rl/R6 show this expression pattern. $|G| l z^{\text {Sprite }} / \mathrm{Y} ; \mathrm{AE} 127 /+$. Svp expression in R3 and R4 is repressed so that only the more posteriorly positioned R1 and R6 cells within each cluster express Svp. $(H)$ Dosage dependence of $l z^{\text {Sprite }}$. When the number of copies of $l z^{\text {Sprite }}$ is increased from one to two, the percentage of ommatidia in which both R3 and R4 are converted into R7 increases from $10 \%$ to $73 \%$; the fraction of single conversions is correspondingly reduced.

ium, whereas in $s e v^{d 2}, 1 z^{\text {Sprite }} / \mathrm{Y}$ this number is reduced to $0.6(n=2061)$ (Fig. 1C). We conclude that the development of the converted R7-like cells is partially dependent on the Sev gene product.

To determine whether the extra R7-like cells seen in $l z^{\text {Sprite }}$ are functionally similar to wild-type $\mathrm{R} 7$ cells, we examined $\operatorname{sev}^{d 2}, 1 z^{\text {Sprite }}$ flies in a color choice test. When presented with a choice of UV or visible light, wild-type flies preferentially move toward the UV light (Banerjee et al. 1987). This behavior is caused by the UV sensitivity of R7 cells. Indeed, sev ${ }^{d 2}$ flies, which completely lack R7 cells, migrate toward a source of visible light. When tested, $\operatorname{sev}^{d 2}, 1 z^{\text {sprite }}$ double-mutant flies displayed a wild-type phototactic behavior (not shown), thus confirming that the converted R7-like cells function as R7 photoreceptors.

The assignment of an R7 identity to the converted $\mathrm{R} 7-$ like cells in $l z^{\text {sprite }}$ is, therefore, based on several independent criteria. Morphologically, these cells resemble R7 cells, their fate is at least partially dependent on Sev, and they function as R7 in behavioral tests. Furthermore, the converted cells in $1 z^{\text {Sprite }}$ result from a lack of Svp in R3 and R4, and other studies have shown that in the absence of Svp, transformations of outer cells give rise to true R7 cells (Mlodzik et al. 1990).
Sprite is an allele $\mathrm{lz}$

To identify the genetic basis for the Sprite phenotype, we used inverse PCR (Ochman et al. 1988) to isolate genomic sequences flanking the P element. A Drosophila genomic library was then probed with these sequences, and overlapping phage clones spanning $\sim 50 \mathrm{~kb}$ from the region were characterized (Fig. 2A). Two 7-kb fragments on either side of the P-element insertion site were chosen to screen an eye-antennal disc cDNA library. Six million cDNA clones were screened, and 43 positive clones corresponding to a single cDNA were identified. The longest version of the cDNA, a $3.5-\mathrm{kb}$ clone, was designated c3.5.

c3.5 was subcloned into a P-element transformation vector containing two copies of the $\mathrm{SE}$ and was transformed into wild-type flies. Six independent transformants showed conversion of R3 and R4 cells into R7 (Fig. $1 \mathrm{D} \mid$, reminiscent of $l z^{\text {sprite }}$. This showed that the $l z^{\text {sprite }}$ phenotype was caused by the misexpression in R3 and $\mathrm{R} 4$ of the gene corresponding to $\mathrm{c} 3.5$. The phenotype of $\mathrm{sE}[\mathrm{c} 3.5]$ transformants is more severe than $I z^{\text {Sprite }}$ in that a significant fraction of ommatidia are missing one or two outer cells. This enhanced severity of the eye phenotype probably results from placing the $\mathrm{sE}$ elements 
A

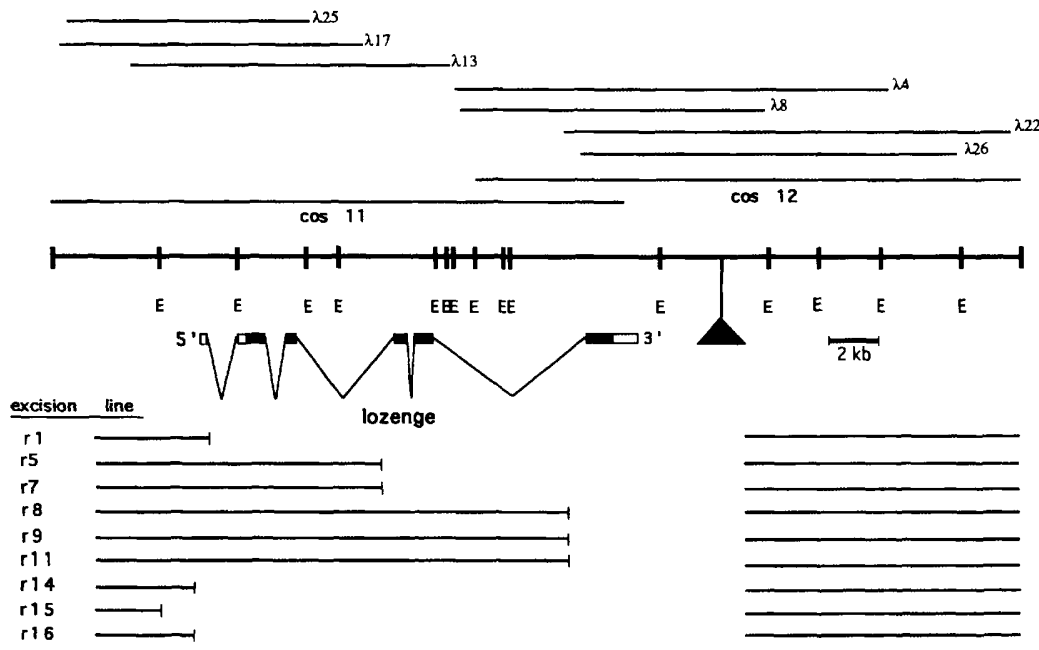

B

1 MHLHLLAVEK TPPSPFPNPT PTPSASPSGH TGAAGESQLD LASQTESQLQ LGLPLASGYG LGLGLGLGLG LGLGQELVAD

81 HSTTVAPVSV AGPGRLGRSI NGSGGSHHHH HLHHHYSPYH HAHPYHPPHP HAPHHHHHH PPYPYPPAGP HPPAMVTSSS

161 TSPTGNGWSS STGDFRGITA VATATGGGVG GATQGATAST GATAAEVLAV SSSASVGSSS PTGGASNGTA HSGHSGHTGG

241 HSSSTASNNN NNNNINGASNS NSMNNNAVHQ DLLWMERLVQ KRQQBHPGEL VRTSNPYFLC SALPAHWRSN KTLPMAFKWY

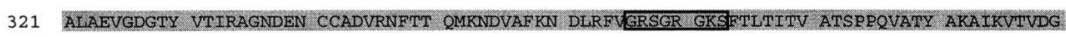

401 PREPRSKTSP TGGPHYRALG LGQRPYIDGF PSTKALHELE SLRRSAKVAA VTTAAAAAAT AASAANAVAA AAAAVAVTPT

481 GGGGGVAAGG GAGGAGAGLV QQLSSNYSSP NSTINSDCQV YKPNAPHIQA AEMMGAGEWT NGSSSSAAAY YHSHAHHPHA

561 HHAHAHLQHQ MALPPPPPPP AAAPVSVGVG GNGATMGMGM GVGVGMGMNH YGGGYDSANS LEAGQYAATC RRCCPRCMAM

641 DSPPIPTRRP AMAVAIRAEA VHPNRNWTTA AATIRRGRMA IRTISMAVVW PPPSTVLRRP PPQPPPPPPV VLCPQLYSTV

721 NQNQIHLHLH SSEKLEQYLG TATSADHLTI GSLTGSSRSS IEIGODOYHO OVHHA00000 $0000000 \mathrm{VHH}$ PO000VESAG

801 EVGGSGAGGV ESAREEDVGD LSQVWRPY

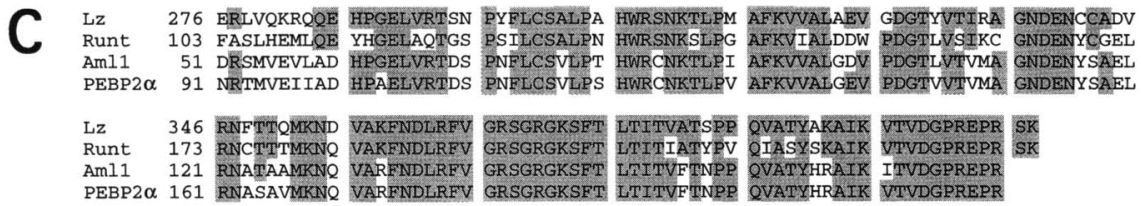

Figure 2. Molecular characterization and sequence analysis of $l z$. (A) The $\sim 50-\mathrm{kb}$ genomic region encompassing $\mathrm{c} 3.5$. On this diagram, the telomeric side is to the right. (E) EcoRI. The gene contains six exons, the shaded regions representing coding sequences, and the clear regions show untranslated sequences. The position of the $\mathrm{P}$ element that gave rise to $l z^{\text {sprite }}$ is indicated by the large, solid triangle. Nine deletions generated by excising the P element are also shown. (B) Predicted amino acid sequence of $\mathrm{Lz}$. The region of highest homology with AML1 is shaded. This region includes the dimerization and DNAbinding domain, as well as a putative ATPbinding site (boxed) which is completely conserved between proteins of this group. The conserved amino acids VWRPY at the carboxyl terminus are indicated by asterisks. Glutamine- and alanine-rich regions are underlined. $|C| \mathrm{A}$ comparison among the Lz, Runt, AMLl, and PEBP $2 \alpha A$ proteins within the Runt homology domain. Identical amino acids are indicated by shaded boxes. directly upstream of $\mathrm{c} 3.5$, whereas in $1 z^{\text {Sprite }}$ flies, the $\mathrm{P}$ element is $\sim 25 \mathrm{~kb}$ downstream from the $5^{\prime}$ end of the coding sequence.

To define a role for the gene encoding c3.5 in eye development, we generated deletions by mobilizing the $1 z^{\text {sprite }}$ P-element. The deletions that affect $\mathrm{c} 3.5$ were mapped by Southern blot and PCR analysis and are shown in Figure 2A. All nine deletion alleles are viable, and the adult flies have smooth eye surfaces lacking lenses and the ommatidial array (Fig. 3B). Additionally, these flies were found to have a partial or complete loss of tarsal claws in the leg, a reduction of the third antennal segment, and a partial loss of female fertility. These phenotypes are all observed in mutations in $1 z$, a locus that maps to 8D8-9 (Lindsley and Zimm 1992) and whose complex genetics and mutant phenotypes have been described recently (Batterham et al. 1995; Gupta and Rodrigues 1995). To test whether the deletion mutants were allelic to $l z$, we mated the deletion allele $r 1$, which lacks the entire coding region of $\mathrm{c} 3.5$ (Fig. 2A), to different alleles of $l z$ characterized previously (see Materials and methods). The resulting trans-heterozygotes had an eye phenotype typical of $l z$ alleles. The failure of $r 1$ to complement $l z$ establishes that $c 3.5$ corresponds to the $l z$ gene and that $r 1$ is a null allele of $l z$. This was confirmed by P-element-mediated transformation. Because the genomic region encoding c3.5 is rather large, we placed the cDNA in the pGMR transformation vector. This vector contains multimerized glass-binding sites, which cause expression of a gene under their control in all cells at the morphogenetic furrow and those posterior to it in the eye disc (Hay et al. 1994). One copy of pGMR $[\mathrm{c} 3.5]$ rescues the external eye phenotype of $l z^{11}$ (Fig. $3 \mathrm{C}$ ), giving rise to a fly in which the ommatidial lattice is restored. The slight roughness of pGMR[c3.5] eyes is attributable to the fact that $\mathrm{c} 3.5$ is under the control of a heterologous enhancer. Internally, the $l z^{r 1}$ photoreceptor cell defect (Fig. IE) is also rescued, but again, because 
Figure 3. c3.5 Rescues the eye phenotype of $l z^{r l}$. $(A-C)$ Scanning electron micrographs of adult eyes. (A) Wild type. These eyes show a repetitive pattern of lenses and a regular ommatidial lattice. $(B) \mid z^{r 1} /$ $Y$. The faceted structure seen in wild type is completely eliminated. The smooth surface of the eye also lacks bristles, lenses, and much of its pigment. (C) $l z^{r 1} / \mathrm{Y}$; pGMR[c3.5]. The ommatidial lattice is restored with only a small amount of roughness. Bristles, lenses, and pigment cells are restored. Bar, $70 \mu \mathrm{m}$.

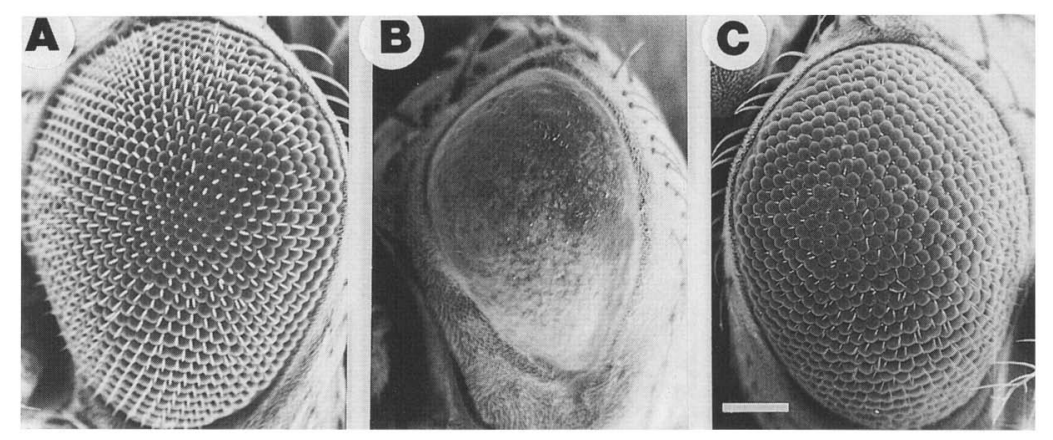

of its misexpression by the GMR enhancer, the phenotype is more similar to $l z^{\text {Sprite }}$ than wild type /data not shown). Taken together, the excision analysis, complementation tests, and rescue experiments establish that c3.5 corresponds to the $l z$ gene and that the $l z^{\text {Sprite }}$ phenotype results when this gene product is expressed at elevated levels in the R3/R4 precursors. The observation that $\mathrm{R} 1 / \mathrm{R} 6$ are not converted into $\mathrm{R} 7$ in $l z^{\text {sprite }}$ cannot be attributed simply to the fact that the sE element causes expression in R1/R6 at a significantly lower level than in R3/R4 (Tomlinson et al. 1987). In pGMR [c3.5] transformants, which express the $\mathrm{Lz}$ protein at similar levels in all cells behind the furrow, the expression of Svp in R3/ $\mathrm{R} 4$ is abolished, but the expression in R1/R6 is still intact (not shown). Therefore, when misexpressed, Lz can negatively regulate $s v p$ in R3/R4. In contrast, $s v p$ cannot be negatively regulated by $\mathrm{L} z$ in $\mathrm{R} 1 / \mathrm{R} 6$.

The expression level of $l z$ is expected to be low, as we failed to detect the $l z$ message on RNA blots under conditions that produced strong signals with the Son of sevenless cDNA used as a control. Similarly, in situ hybridization to RNA in the eye disc did not give a signal detectable above the background.

\section{$L z$ belongs to the AML1/Runt family of transcription factors}

The $1 z$ cDNA sequence contains a single open reading frame (ORF) of 2559 nucleotides (GenBank accession no. U47849). The first methionine is found 78 nucleotides downstream of where the ORF begins, predicting a protein of 828 amino acids (Fig. 2B). Sequence analysis revealed that the central portion of the molecule shows a striking similarity to a domain found in a family of proteins that have been shown to function as transcriptional regulators (Kagoshima et al. 1993). The sequence similarity is in a putative DNA-binding, protein dimerization, and ATP-binding domain (Fig. 2C). The members of this family include the Drosophila Runt protein (Kania et al. 1990), where this domain was first identified; AMLl (acute myeloid leukemia 1 ), which has been implicated in the etiology of human leukemias (for review, see Nucifora and Rowley 1995), and the murine protein PEBP2 $\alpha \mathrm{A}$ (polyomavirus enhancer-binding protein $2 \alpha \mathrm{A}$ ) (Ogawa et al. 1993a). The AML1 gene is the most frequent target of translocations that have been linked to acute myelogenous leukemia and plays a role in many important steps leading to hematopoietic cell differentiation and proliferation (Okuda et al. 1996 and references therein). In the homologous domain, Lz has $71 \%(94 / 132$ amino acids) identity to AMLl and 69\% (91/132 amino acids) identity to Runt. The $\mathrm{Lz}$ sequence also possesses an alanine-rich stretch and a glutamine-rich region in the carboxy-terminal portion of the molecule. Glutamine- and alanine-rich stretches have been found together in many transcriptional repressors, including the Drosophila Giant, Eve, and AEF-1 proteins (Capovilla et al. 1992; Falb and Maniatis 1992; Han and Manley 1993). The last five amino acids of the predicted protein are VWRPY, a motif with unknown function that is conserved in all genes belonging to this family.

\section{Lz negatively regulates Svp}

In $1 z^{\text {Sirte }}$ mutants, failure of the $\mathrm{R} 3 / \mathrm{R} 4$ precursors to express Svp causes them to become R7 neurons. Because this appears to be the result of ectopic expression of the $\mathrm{Lz}$ gene product in R3/R4, we reasoned that the loss of $l z$ gene function could also affect $s v p$ expression. Therefore, the svp-lacZ enhancer-trap line AE 127 was combined with the null allele $l z^{r 1}$. Eye discs from $l z^{r 1} / Y$; AE127/ + larvae were stained with an antibody against $\beta$-galactosidase and were compared with staining in $\mathrm{AE} 127 /+\left(\right.$ Fig. 4A,B). We found that in a $l z^{r 1}$ background, expression of Svp is not limited to R1/R6 and R3/R4 but can be detected in nine cells in each cluster (Fig. 4C-E). As in wild type, Svp expression in $l z^{r 1}$ initiated in R3/R4 and $\mathrm{R} 1 / \mathrm{R} 6$, but posteriorly the $\mathrm{R} 7$ and cone cell precursors were also found to express Svp.

We stained $l z^{r 1} / Y$ eye discs using the ELAV antibody as a marker for neuronal differentiation. In wild-type discs, this antibody stains the nuclei of the eight photoreceptor precursors (Fig. $4 \mathrm{~F}, \mathrm{G}$ ). In $l z^{11} / \mathrm{Y}$ discs the initial staining in $\mathrm{R}$ cells appears to be as in wild type, but later, two to four cone cells in each cluster also exhibit ELAV staining (Fig. $4 \mathrm{H}-\mathrm{J}$ ).

To determine whether cone cell-specific markers are expressed, we stained $l z^{r 1} / Y$ discs using an antibody against Cut (Blochlinger et al. 1993). In wild-type discs, this antibody stains the four cone cell precursors in each cluster (Fig. $4 \mathrm{~K}, \mathrm{~L}$ ), whereas in $l z^{r 1} / \mathrm{Y}$ discs, no staining with this antibody can be detected (Fig. 4M,N). Thus, no cone cells develop in $l z^{r 1} / Y$ discs, consistent with the observation that their precursors express Svp and ELAV 


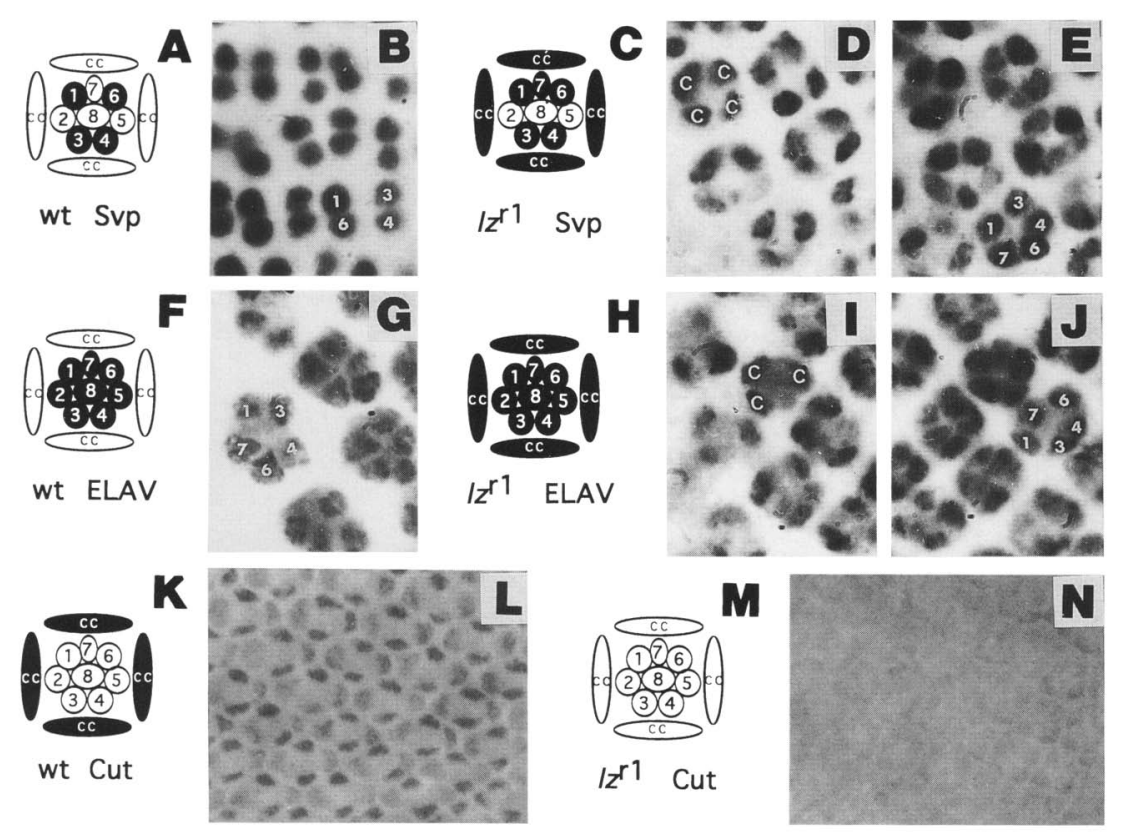

Figure 4. Expression of neuronal and cone cell markers in $l z^{r 1}$. $(A-E)$ Staining pattern and schematic representation of Svp expression. $\{A, B \mid$ Wild type. $|A|$ Schematic representation of the expression pattern of Svp within a wild-type ommatidium. $(B)$ The corresponding Svp expression pattern in R3, $R 4, R 1$, and $R 6$ in an eye imaginal disc from the svp-lac $Z$ enhancer trap strain of genotype AE127/ + stained with an antibody against $\beta$-galactosidase. (C) $l z^{r 1} / Y$. A schematic representation shows that in addition to R3, R4, R1, and R6, the R7 and cone cells now express Svp in a $l z^{r 1}$ ommatidial cluster. $(D)$ In an apical focal plane, Svp expression is detected in all four cone cells. $(E)$ In a more basal focal plane of the same clusters shown in $D$, the R7 cell can also be seen to express Svp. $(F-f)$ Staining pattern and schematic representation of ELAV expression. $(F, G)$ Wild type. (F) All photoreceptor nuclei stain with an antibody against $\operatorname{ELAV}(G)$ Staining in R1, R6, R3, R4, and R7 is observed in the focal plane shown. R2, R5, and $\mathrm{R} 8$ nuclei also stain and are in a different plane of focus at this stage (not shown). $\left(H-\| l z^{r l} / \mathrm{Y} .(H)\right.$ In $l z^{r 1}$ discs, ELAV is expressed not only in R1-R8 but also in cone cell precursors. (I) At the cone cell level, three or four cone cell precursors are found to stain with this neuronal marker. $(J)$ At the photoreceptor cell level, R3, R4, R1, R6, and R7 stain for ELAV. As in wild type, R2, R5, and R8 also stain with ELAV, but their nuclei are at a more basal level and are not shown here. $(K-N)$ Staining pattern and schematic representation of Cut expression. $(K, L)$ Wild type. Four cone cells in each cluster stain with an antibody against the Cut protein. $(M, N)$ In $l z^{r l}$ discs, the cone cell precursors no longer stain with the Cut antibody. This is consistent with the finding that these cells express ELAV and Svp $(G, I)$ and suggests that in $l z^{r 1}$, the cone cell precursors are reprogrammed to initiate a neuronal fate. Posterior is to the left in all discs.

and indicating that they make an alternative developmental choice to become neurons. The absence of proper cone cell development in discs explains the adult phenotype of $l z$, which is completely lacking these lenssecreting cells. The disorganized morphology of $\mathrm{R}$ cells in the adult eye is likely to be a secondary effect of this developmental phenotype and may result from cell death or from cell loss in the retina because of the absence of supporting cone and pigment cells. If cell death is responsible, it must be a late event, as acridine-orange staining of $l z^{r 1}$ third instar and 4-hr pupal eye discs did not show any significant difference in the pattern of cell death compared to wild type (not shown).

In summary, the developmental analysis of $l z$ eye discs suggests that $\mathrm{L} z$ functions as a negative regulator of Svp in R7 and cone cell precursors. Moreover, the lack of $l z$ function causes a change in cone cell fate, inducing them to take on a neuronal identity.

\section{Interaction of $1 z^{\text {sprite }}$ with ras 1}

Begemann et al. (1995) and Kramer et al. (1995) have suggested a synergistic interaction between $s v p$ and members of the ras pathway (see Discussion). We examined this by combining $l z^{\text {sprite }}$ with ras 1 . Whereas only $5 \%(n=1821)$ of $1 z^{\text {Sprite }}$ ommatidia contain fewer than the normal complement of $\mathrm{R}$ cells, in a $1 z^{\text {Sprite }}$; ras $1^{e 1 b} /+$ background, $83 \%(n=2126)$ of the ommatidia have lost at least one photoreceptor cell (Fig. 5A,B). This is a significant result, because removing one copy of ras1 normally has no phenotypic consequences for the fly. Although the alteration of the geometry of the ommatidial array makes it difficult to assign exact identities to the lost cells, it is reasonable to speculate that many of the R3 and R4 cells that are converted to R7 in $l z^{\text {sprite }}$ fail to differentiate as neurons in $I z^{\text {Sprite }} / Y_{;}$ras $1^{\text {elb }} /+$. Thus, both Ras signaling and Svp activity are important in the specification of neuronal identity.

To determine whether $l z$ belonged to the ras pathway as a downstream member, we created flies that were $l z^{r 1}$ / + ; $\mathrm{s}\left[\operatorname{ras}^{\text {val12 }}\right]$. In $\mathrm{sE}\left[\right.$ ras $\left.^{\text {val12 }}\right]$ flies, the activated ras1 allele, ras $1^{\text {val12 }}$, is under the control of the sev enhancer, which results in an external roughening of the eye. Internally, an average of three to four cone cells in each ommatidium are converted to R7 (Fortini et al. 1992). $1 z^{r 1} /+; \mathrm{sE}\left[\right.$ ras $\left.^{\text {val12 }}\right]$ flies have an external eye phenotype that is indistinguishable from $\mathrm{sE}\left[\right.$ ras $1^{\text {val12 }}$ ] (data not shown). The cone to $\mathrm{R} 7$ conversion is also virtually unchanged from $\mathrm{sE}\left[\operatorname{ras}^{\text {val12 }}\right]$. In this assay downstream elements of the ras pathway, such as members of the kinase cascade, significantly suppress the $\mathrm{sE}\left[\right.$ ras $\left.^{\text {val12 }}\right]$ phenotype (Therrien et al. 1995). Therefore, we conclude that $l z$ does not belong directly in the ras pathway.

To test whether the ras pathway affects Svp expression, we stained sE[ras $\left.1^{\text {val12 }}\right] ;$ AE127/ + discs for Svp. In a small but reproducible number of clusters in these 
discs, we found ectopic staining of Svp in one or two cells (Fig. 5C). This is consistent with earlier observations by Y. Hiromi (pers. comm.). Of 160 clusters counted, 38 displayed one extra cell and 3 two extra cells staining with Svp. This ectopic expression of Svp is not the basis for the $\mathrm{sE}\left[\right.$ ras $\left.^{\text {val12 }}\right]$ phenotype because the number of additional cells expressing Svp in $\mathrm{SE}\left[\right.$ ras $\left.^{\text {val12 }}\right]$ discs is far fewer than the number of extra $R 7$ cells that are seen in each ommatidium of the adult. Nevertheless, this observation suggests that under some circumstances Svp could be a downstream target of the Ras pathway (see Discussion).

\section{Role of $\mathrm{Lz}$ in cell fate determination}

To determine the functional requirement of $\mathrm{L} z$ in individual photoreceptor cells, we generated clones homozy. gous for $l z^{r 1}$ (Fig. 6B) in an otherwise wild-type eye. In these mosaic eyes, ommatidia that lie along the patch border are comprised of both mutant and wild-type cells. Cells that express functional $\mathrm{Lz}$ product are marked with the $w^{+}$gene and appear pigmented. Those cells that are $l z^{-} / 1 z^{-}$lack pigment granules. Along the clone border, we examined mosaic ommatidia that contained a normal complement of photoreceptor cells. The results are summarized in Figure 6A and suggest an absolute requirement of $l z$ gene function for proper development of R7. The R1/R6 cells show a strong preference for being wild type (see next section). Cone cells cannot be scored for pigment granules, but on the basis of our other results, we expect they will autonomously require $\mathrm{Lz}$ as well. Importantly, R8, R2/R5, and R3/R4 develop normally even when they are $l z^{-} / 1 z^{-}$, indicating that they do not require $\mathrm{L} z$ function for their differentiation.

Aberrant mosaic ommatidia along patch borders were often found to contain seven or more outer photoreceptors (Fig. 6C,D). In several of these, no R7 cells were seen, but instead, one extra outer cell was found. Presumably, in these ommatidia the R7 precursor was $l z^{-}$, $\mathrm{Iz}^{-}$and was therefore converted into an outer photoreceptor neuron. More than one extra outer cell is sometimes found in these aberrant ommatidia. These additional cells are likely to have arisen from cone cell precursors that have been fated to become outer cells.
These phenotypes are similar to the R7 and cone-toouter-cell conversions observed previously when Svp was expressed ectopically in the $R 7$ and cone cell precursors (Begemann et al. 1995; Kramer et al. 1995).

In principle, $1 z$ mutant alleles should also show the $\mathrm{R} 7$ or cone-to-outer-cell conversions seen above. The $l z^{r 1}$ eye is too disrupted to observe these phenotypes. In sections of weaker alleles of $l z$, however, we can find conversions of both kinds. In the weakest allele tested, $l z^{k}$, the eye is largely wild type with an occasional ommatidium showing an extra R7 cell (Fig. 6E). In a stronger allele such as $1 z^{34}$, clear examples of a cell in the position of $\mathrm{R} 7$ being converted to an outer cell can be seen (Fig. $6 \mathrm{~F}$ ). In an even stronger allele such as $l z^{3}$, many extra outer cells can be found (Fig. 6G), presumably because of the transformation of one or more cone cell precursors into outer cell types. Together, the clonal analysis and the phenotypic analysis of weak alleles suggest that in $l z$ mutants, svp expression in R7 and the cone cell precursors ultimately alters cell fate. In stronger $l z$ alleles, $s v p$ is expected to be expressed at higher levels, and the cells adopt an outer cell fate much as they do when $s v p$ is expressed ectopically in them at high levels (Begemann et al. 1995; Kramer et al. 1995). In weaker $l z$ alleles, svp is expressed at lower levels and so cone cells are converted into $R 7$ cells, as is seen with mild overexpression of svp (Begemann et al. 1995; Kramer et al. 1995). In generating homozygous clones of $l z$ in the eye (Fig. 6AD), we have used the null allele $r$, and thus, all observed conversions of cone cells are into an outer cell type.

\section{$L z$ positively regulates Bar}

Although the majority of the observed $l z$ phenotypes can be readily explained by the negative regulation of $s v p$, it is unlikely that $s v p$ is the only gene controlled by Lz. Upon ectopic expression of $\mathrm{Lz}$, one observes some loss of outer cells. This is not seen in svp loss-of-function clones in the eye (Mlodzik et al. 1990). Similarly, the $l z$ null phenotype in the eye is more severe than that observed with overexpression of Svp. These differences can be explained if $\mathrm{Lz}$ were to control other genes that are important for the development of the eye. In addition to this observation, our clonal analysis showed that $\sim 90 \%$
Figure 5. Effects of ras 1 on $1 z^{\text {Sprite }}$ and $s v p$ expression. (A) Tangential section of a $l z^{\text {Sprite }} / \mathrm{Y} ; \operatorname{ras} 1^{e 1 b} /+$ eye. The removal of one copy of ras $1^{e 1 b}$ results in a majority of the ommatidia lacking usually one (arrow), but sometimes two (arrowhead), photoreceptor cells. $|B|$ In $1 z^{\text {sprite }} / Y$, only $5 \%$ of the ommatidia are missing outer cells, but $83 \%$ lack one or more $\mathrm{R}$ cells in $1 z^{\text {sprite }} / \mathrm{Y}$; ras1 $1^{\text {e1b }} /+$. (C) sE[ras Val12]; AE127/ + eye disc stained to visualize Svp expression. In addition to R3, R4, R1, and R6, an extra cell (arrow) expresses Svp in 25\% of the ommatidial clusters.
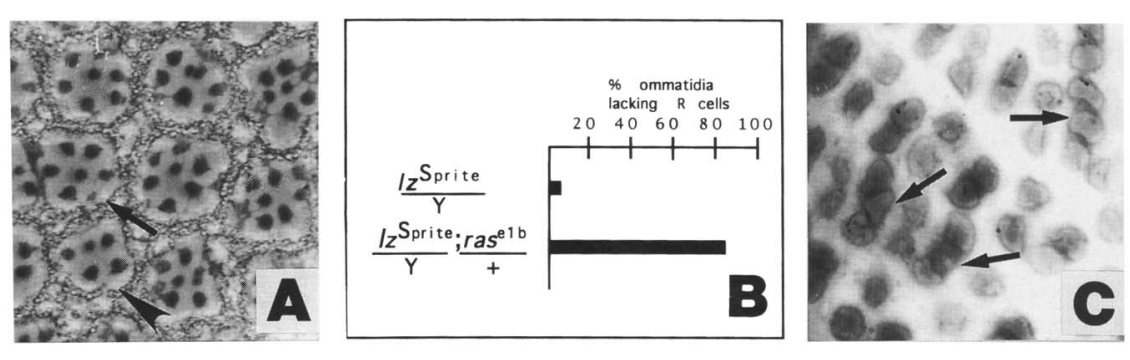


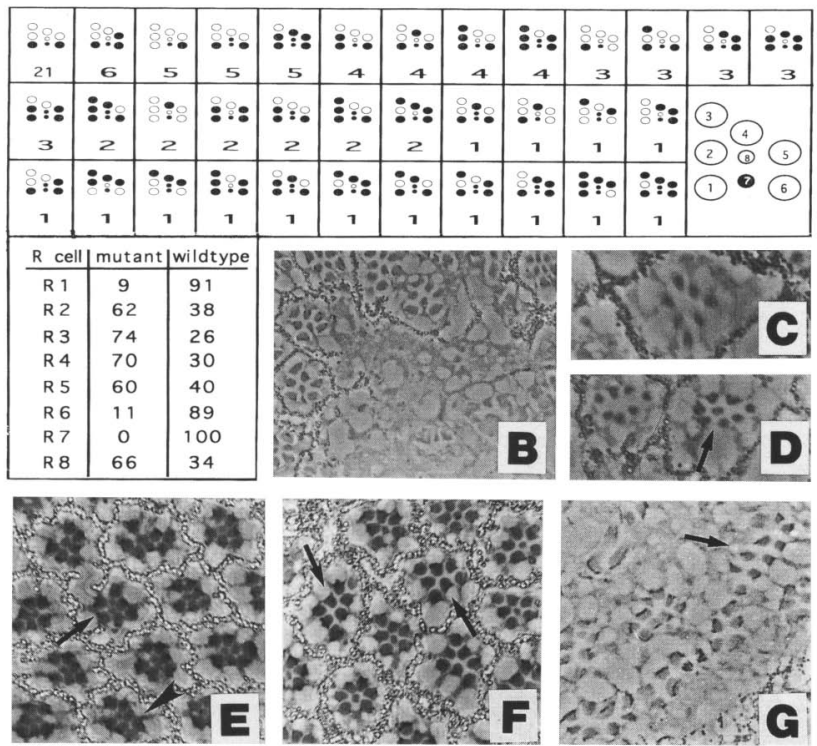

Figure 6. Clonal and phenotypic analysis of $l z$ function. $|A| \mathrm{A}$ total of 100 phenotypically wild-type, but genetically mosaic, border ommatidia were examined, and the $\mathrm{R}$ cells within them were classified on the basis of the presence or absence of pigment granules. Cells lacking pigment granules are genotypically $W^{-}$and $l z^{-}$and are represented by open circles in this diagram. R7 was the only cell never found to be genetically $l z^{-} / l z^{-}$in any of the phenotypically normal border ommatidia examined. The large schematic of a single ommatidium shows the identity of the cells and indicates the autonomy of $l z$ function in $\mathrm{R} 7$. (B) Tangential section through a $l z^{r 1} / 1 z^{r 1}$ clone. Along the clonal border are several phenotypically normal but genotypically mixed ommatidia. $|C, D|$ Three examples of aberrant ommatidia along the border of a $l z^{r l} / l z^{r l}$ clone. These ommatidia contain seven rather than six outer cells. In addition, one of them (arrow) also contains a central R7 cell. (E-G) Adult eyes of hypomorphic $l z$ mutants. $(E) I z^{k} / Y$. This is the weakest $l z$ allele isolated. A small fraction of the ommatidia has a supernumerary R7 cell (arrows). Also, ommatidia are occasionally observed that have an extra outer cell (arrowheads). $(F) l z^{34} / Y$. Many examples of conversions of $\mathrm{R} 7$ cells into an outer cell can be seen (arrows). (G) $1 z^{3} / Y$. These eyes are disrupted quite severely. The ommatidium shown (arrow) contains at least eight photoreceptor cells.

of R1/R6 cells did not differentiate when lacking the $l z$ gene product (Fig. 6A), suggesting that R1/R6 cells have a strong, although not absolute, requirement for Lz. A gene product required specifically in $\mathrm{R} 1 / \mathrm{R} 6$ cells to specify their fate is the homeo domain protein Bar (Higashijima et al. 1992). To establish whether $\mathrm{Lz}$ was implicated in transcriptionally regulating this protein, $l z^{r 1}$ discs were stained with an antibody against Bar. We found that in $1 z^{r 1}$ discs the expression level of Bar in R1/R6 was reduced dramatically (Fig. $7 \mathrm{C}, \mathrm{D}$ ), but not completely eliminated, when compared with wild-type controls (Fig. 7A,B). Thus, $\mathrm{Lz}$ is needed for high levels of expression of Bar. This is consistent with the partial requirement of $l z$ in R1/R6 uncovered by mosaic analysis. Because the $\mathrm{S} 12$ antibody was raised against $B a r H 1$, it is formally possi- ble that $\mathrm{Lz}$ only regulates one of the two coordinately controlled Bar genes. Our results raised the possibility that upon overexpression of $\mathrm{Lz}$, ectopic Bar staining might be seen. In pGMR[c3.5] discs Bar expression was no longer restricted to R1/R6, but ectopically staining cells were consistently detected in the developing clusters (Fig. 7E). Therefore, Lz normally functions in R1/R6 as a positive regulator of $B a r$, and $\mathrm{Lz}$ misexpression can lead to ectopic Bar expression, consistent with the hy. pothesis that Bar represents a second target of $\mathrm{Lz}$.

\section{Discussion}

\section{Lz controls svp and Bar expression}

An early step of pattern formation in the eye disc is the creation of equivalence groups of cells. Individual cell fates are selected from within each group by intercellular signaling mechanisms. Ultimately, the control of this prepatterning is at the level of transcription factors. Thus, Svp is expressed in R1/R6 and R3/R4 and is important for their fate; Bar is expressed in Rl/R6 and is required for their proper differentiation (Higashijma et al. 1992). Because these transcription factors are expressed in specific precursor cells, they themselves cannot be responsible for the specification of equivalence groups of cells. Cell-fate specificity must be derived

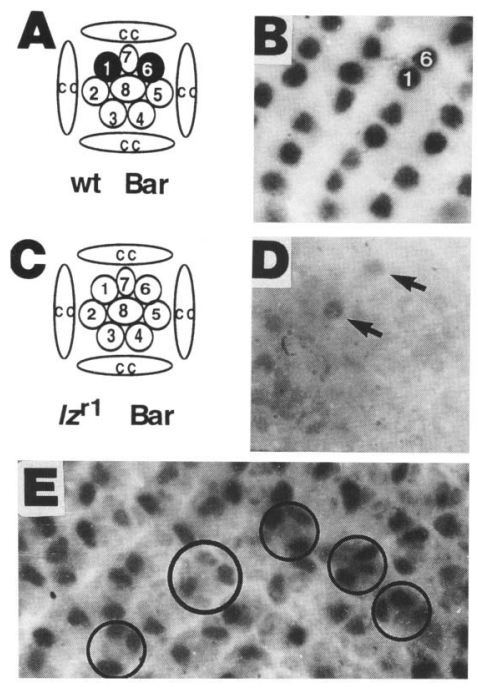

Figure 7. Positive regulation of Bar by Lz. $(A-D)$ Schematic representation and staining pattern of Bar expression. $|A, B|$ Wild type. $(A)$ The expression pattern of Bar in a wild-type ommatidium is represented schematically. $(B)$ The corresponding pattern of Bar expression in R1 and R6 is shown in a wild-type eye imaginal disc stained with the Bar antibody $S 12$. $(C, D) 1 z^{11} / \mathbf{Y}$. $(C)$ A schematic representation indicating that in a $l z^{r^{1}}$ ommatidial cluster, Bar is not expressed in R1/R6. (D) Staining of a $l z^{r 1}$ disc with the S12 antibody shows that Bar expression is severely reduced compared to wild type, but not abolished completely (arrows). (E) A pGMR $|l z| / \mathrm{pGMR}[|z|$ eye disc stained with the $\mathrm{S} 12$ antibody. Ectopic Bar staining can be seen in several ommatidia (circled) 
through the coordinate control of the expression of these genes by other transcription factors.

In this study we have characterized molecularly the $l z$ gene and its predicted protein product and have demonstrated that it functions to negatively regulate Svp expression and positively regulate Bar expression in distinct sets of cells within the same cluster, in the Drosophila eye imaginal disc. We have demonstrated that there is an absolute requirement for $l z$ in $\mathrm{R} 7$ and cone cell precursors, where, in its absence, $s v p$ is expressed, causing an alteration of cell fate. In addition, we have shown a partial requirement for $l z$ in the proper development of the R1/R6 photoreceptors.

Phenotypes resulting from an overexpression of $s v p$ are remarkably similar to those seen in loss-of-function alleles of $l z$. Similarly, many parallels can be found between the eye phenotype resulting from $s v p$ loss of function and misexpression of the $l z$ gene product. This further substantiates the view that $l z$ is a negative regulator of $s v p$. Thus, R3 and R4 cells are converted into R7 when $l z$ is expressed in precursors for those cells, or when the Svp product is missing from them. Likewise, the conversion of cone cell precursors into an R7 or outer cell type, and the conversion of $\mathrm{R} 7$ precursors into outer cell types is seen with $l z$ loss-of-function alleles as well as when $s v p$ is expressed ectopically in the R7 and cone cell precursors. These results suggest that Svp is essentially a neuronal determinant but, when expressed at high levels, activates genes that are specifically required for outer cell development.

The coordinate control of the expression of $s v p$ and Bar by Lz leads ultimately to the proper patterning of the cells deriving from the second wave of mitotic division. This is achieved by the negative regulation of Svp in the $\mathrm{R} 7$ equivalence group, which allows these cells to be competent to respond to the Sev signal and, at the same time, by the positive regulation of Bar, thereby distinguishing the precursors of $\mathrm{R} 1$ and $\mathrm{R} 6$ from those of the R7 equivalence group.

The nature of the $\mathrm{Lz}$ gene product strongly argues that it functions as a transcription factor. The fact that both loss of $\mathrm{Lz}$ and misexpression of $\mathrm{Lz}$ cause alterations in the expression patterns of Svp and Bar suggests a direct transcriptional regulation of these two genes by Lz. Our analysis, however, cannot rule out the mediation of intermediary factors, which upon activation by Lz, act to control $s v p$ and Bar transcription. Future biochemical analysis will be needed to resolve this issue. Proteins that are similar to $\mathrm{Lz}$ have been shown to function as heterodimers, and any biochemical analysis with $\mathrm{Lz}$ will have to await the characterization of its proper partner.

\section{$L z$ is related to $A M L 1$ and Runt}

Sequence analysis of the predicted protein product revealed that $\mathrm{L} z$ contains a region with striking homology to the DNA-binding and protein dimerization domains of an emerging family of transcription factors. This group includes runt, a gene involved in segmentation and sex determination in Drosophila, and AMLl, trans- locations in which have been associated with human leukemias. There is evidence that like $\mathrm{Lz}$, both Runt and PEBP $2 \alpha$ can function as repressors as well as transcriptional activators (Tsai and Gergen 1994; Takahashi et al. 1995). PEBP2 $\alpha$ and AML1 recognize a consensus site, $\mathrm{Pu} / \mathrm{TACCPuCA}$, which is contained in enhancers of T-cell-receptor genes (Satake et al. 1992). The regulatory regions of svp and Bar have not been sequenced, so it is not clear whether such a consensus is contained within them. It is interesting that $\mathrm{Lz}$ contains an alanine-rich region followed by a glutamine-rich stretch near its carboxyl terminus, as these sequences are often found together in transcriptional repressors. Such stretches are not found in either Runt or AMLl but are found in PEBP2 $\alpha$ (Ogawa et al. 1993a).

Both AMLl and PEBP2 $\alpha$ have been shown to function as heterodimers. PEBP $2 \alpha$ can bind DNA on its own, but its transcriptional activity is enhanced when bound as a heterodimer with its structurally unrelated partner PEBP2 $\beta$ (Ogawa et al. 1993b). The DNA-binding domain of the product of the Drosophila gene runt is so structurally related to that of PEBP $2 \alpha$ that it can bind the murine $\beta$ subunit (Kagoshima et al. 1993). It is reasonable to propose that a $\beta$ subunit partner exists for $L z$, and that the two gene products function together to regulate svp and Bar expression. In this scenario, the differential expression or activation of $\mathrm{Lz}$ and/or its partner could provide one possible mechanism for spatially restricting the negative regulation of $s v p$ to the $\mathrm{R} 7$ equivalence group and the positive regulation of Bar to Rl and R6 in the developing eye imaginal disc.

\section{$L z$ specifies the $R 7$ equivalence group}

The R3 and R4 precursors express Sev and are in spatial proximity to the Boss-expressing R8 cell, yet they do not normally become R7 cells. These cells do need a Ras signal to develop as neurons (Simon et al. 1991), but the expression of Svp causes them to interpret this signal in the context of $\mathrm{R} 3 / \mathrm{R} 4$ development. When $s v p$ is expressed in the $\mathrm{R} 7$ precursor, it acts as a cell fate-switching molecule, transforming $\mathrm{R} 7$ into an outer cell. Lz has no functional role in R3 and R4 at all, where Svp function is essential. Instead, $\mathrm{Lz}$ appears to operate in the specification of the R7 equivalence group by keeping Svp transcriptionally turned off in these cells. This is a powerful mechanism for generating diversity among cells that may potentially be receiving qualitatively similar signals for neuronal determination.

The fact that the converted $\mathrm{R} 7$ cells in $1 z^{\text {Sprite }}$ are partially dependent on Sev suggests that these precursors can interpret the Sev RTK signal in the context of R7 development when Svp is removed from them. The fact that the dependence on Sev is only partial suggests that these precursors receive additional Ras signals, perhaps originating from the epidermal growth factor (EGF) receptor. The requirement for RTK signals for the development of these photoreceptor cells was also demonstrated in the observed genetic interaction between $1 z^{\text {sprite }}$ and ras 1 . Clearly, both Ras and $\mathrm{Lz}$ are important 
for the development of photoreceptor cells. Because cone cell precursors can be converted into $\mathrm{R} 7$ as well as into outer cells by loss of $l z$ or by gain of $s v p$, we concur with Begemann et al. (1995) that the cone cell precursors also require low levels of Ras signal for their proper development, arising again, perhaps from the EGF receptor. These conclusions suggest a combinatorial mechanism for cell fate specification involving the activities of the $\mathrm{Lz}$ and the Ras pathway (Fig. 8A).

The exact molecular relationship between the Ras pathway and $\mathrm{Lz}$ is not yet clear, although several models can be proposed to explain the synergistic role of these two proteins in the specification of neuronal fate. One scenario, that $\mathrm{Lz}$ could be a downstream target of the Ras signal, is not supported by our results. In genetic assays, the interaction between ras 1 and $l z$ is much weaker than would be expected if they belonged to the same pathway. Two likely models are shown in Figure $8 \mathrm{~B}$. In model I, the Ras and Lz pathways are essentially parallel, intersecting only at a level downstream of Svp. In this scheme, $\mathrm{Lz}$ would function to negatively regulate $s v p$, but the Ras pathway will have no direct effect on this gene. Rather, some molecules farther downstream could be regulated together by the Ras pathway and Svp.

In model II, the transcriptional regulation of Svp is under the positive control of a downstream member of the Ras pathway and concurrently under the negative regulation of $\mathrm{Lz}$. In this model the Ras pathway can activate Svp only when Lz inhibition is rescinded. The sporadic overexpression of $\mathrm{Svp}$ in a $\mathrm{sE}\left[\operatorname{ras}^{\text {val12 }}\right]$ mutant background (Fig. 5C) is also consistent with this model, as repression of Svp by $\mathrm{Lz}$ can only be overcome in a few cells even when Ras levels are exceedingly high. This

\begin{tabular}{|c|c|c|c|}
\hline Ras & Lozenge & Seven-up & \\
\hline low & active & off & cone \\
\hline high & active & off & $\rightarrow$ \\
\hline active & off & active & $\rightarrow \mathrm{R} 3 / \mathrm{R} 4$ \\
\hline
\end{tabular}
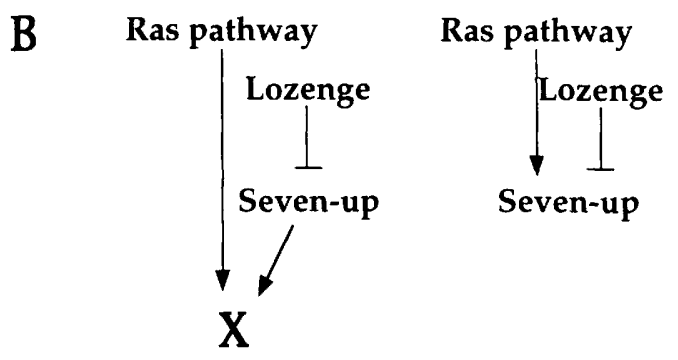

\section{I}

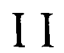

Figure 8. Models for the role of $\mathrm{Lz}$ in cell fate determination. (A) The combination of different levels of activity for Ras, $\mathrm{Lz}$, and Svp leads to cell fate specification. $(B)$ Two possible models illustrating the cooperative role of the Ras pathway and Lz. (see text for details). would not be a prediction of model I, where Svp expression is entirely independent of Ras. Future localization of the $\mathrm{Lz}$ gene product in the eye disc and a biochemical study of its function will be important for testing these models.

The striking sequence similarity between $\mathrm{Lz}$ and AMLl can be extended to the functional role that these proteins play in cell differentiation. The development of hematopoietic cells in mammals appears to have interesting parallels with the development of photoreceptor neurons in the Drosophila eye. In both systems the concerted action of growth factors and AML1-like proteins is important for cell growth and differentiation. In hematopoietic cell lineages, AMLl promotes differentiation in cooperation with growth factor pathways. In the Drosophila eye, Lz works together with the Ras pathway in the regulation of neuronal development. Although the exact mechanisms may differ, the underlying developmental strategies have been remarkably conserved.

\section{Materials and methods}

Molecular characterization of $\mathrm{lz}$

The entire sequence of $\mathrm{c} 3.5$ was determined by use of the Sequenase system (U.S. Biochemical Corporation). Approximate intron/exon boundaries were deduced by use of sequencing primers to amplify regions of the $l z$ gene with genomic DNA as a template and comparison of the sizes of the amplication products to those obtained in similar PCR amplification reactions when the $I z$ cDNA was used as a template. The precise intron/ exon boundaries were then identified by sequencing the appropriate genomic regions.

The molecular lesion in each excision line was mapped approximately by PCR. Primers corresponding to bases 2011-2029 and 2750-2768 from c3.5 were used in PCR amplification reactions to determine whether the $3^{\prime}$ end of the gene was present in each excision line. Similarly, primers corresponding to bases 534-551 and 1005-1022 were used to approximate how far the deletion extended toward the $5^{\prime}$ end of the gene. More precise mapping was done by Southern blot analysis with c3.5 and selected genomic fragments from the region as probes.

\section{Immunohistochemistry and scanning electron microscopy}

Fixation and sectioning of adult eyes were performed as described previously (Coyle-Thompson and Baneriee 1993). Scanning electron microscopy and antibody stainings were performed essentially as described (Rogge et al. 1995).

\section{Generation of transformants and $\mathrm{lz}$ excision alleles}

$W^{1118}$ fernales were mated to $\Delta 2-3 / \Delta 2-3$ males containing a source of transposase, and the resulting embryos were injected

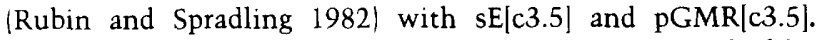
Greater than 10 independent transformants were established for each construct. The pGMR/c3.5] construct was generated by insertion of the c3.5 cDNA in the unique EcoRI site of the pGMR vector, downstream of a pentamer of truncated glassbinding sites and TATA box sequences. $s E[c 3.5]$ was constructed by subcloning of the C3.5 cDNA as an EcoRI fragment into a slightly modified Sev-S1l vector carrying two tandem copies of the $s v l$ enhancer and a heat shock promoter (Basler et al. 19911. 
For generation of imprecise excisions in $l z^{\text {Sprite }}$, the P element was mobilized in $l z^{\text {sprite }} / \mathrm{Y}$ male flies by crossing with females containing transposase $(\Delta 2-3)$, and individual lines representing independent excision events were established. Five hundred seventy-five individual lines were screened, and two complementation classes of imprecise excision lines were characterized. The first class, consisting of nine lines, was found to be viable and represented deletions in $l z$. The second class, comprising eight lines, was lethal. The lethal class was found to represent deletions that mapped distal to $\mathrm{c} 3.5$ (to the right on the map in Fig. 2A) and was therefore not pursued further.

Complementation tests were performed between the four imprecise excision alleles $\mathrm{rl}, \mathrm{r} 9, \mathrm{rll}$, and $\mathrm{rl} 4$ and eight previously characterized alleles of $l z(1, k, g, 34,3,36,37)$. In all cases, the excision allele failed to complement the $1 z$ eye, tarsal claw, and antennal phenotype.

\section{Mosaic analysis}

$w^{1118}, l z^{r 1} / \mathrm{Y}$ males were mated to Oregon $\mathrm{R}\left(\mathrm{w}^{+}, l z^{+} \mid\right.$females. Twelve to 36 -hr first-instar larvae resulting from this cross were irradiated with $\mathrm{X}$-rays $(1200 \mathrm{R})$ to induce mitotic recombination. The frequency of clones was 30 in 159 flies screened.

\section{Acknowledgments}

We are indebted to Lian Liu, Julia Mitrevski, and Yeon Ill Chung for technical assistance and to Bhagwati Gupta for help with phenotypic analysis. We are grateful to the members of our laboratory for helpful comments regarding the manuscript. We thank Gerry Rubin, Michael Simon, Ernst Hafen, and Kathy Matthews for fly stocks and constructs, and Gerry Rubin, Karen Blochlinger, Tetsuya Kohima, Kaoru Saigo, and John Tamkun for antibodies and libraries. We also thank Peter Gergen and Yasushi Hiromi for helpful advice and discussions and John Pollock for communicating unpublished results. C.A.K. is supported by a tumor cell training grant (National Research Service Award 5T32CA09056). U.B. is supported by a National Institutes of Health grant (RO1EY08152-06), and a Faculty Research Award (FRA426) from the American Cancer Society.

The publication costs of this article were defrayed in part by payment of page charges. This article must therefore be hereby marked "advertisement" in accordance with 18 USC section 1734 solely to indicate this fact.

\section{Note}

The GenBank accession number for the sequence reported in this paper is $\mathrm{U} 47849$.

\section{References}

Banerjee, U., P.J. Renfranz, J.A. Pollock, and S. Benzer. 1987. Molecular characterization and expression of sevenless, a gene involved in neuronal pattern formation in the Drosophila eye. Cell 49: 281-291.

Basler, K., D. Yen, A. Tomlinson, and E. Hafen. 1990. Reprogramming cell fate in the developing Drosophila retina: Transformation of R7 cells by ectopic expression of rough. Genes \& Dev. 4: 728-739.

Basler, K., B. Christen, and E. Hafen. 1991. Ligand-independent activation of the sevenless receptor tyrosine kinase changes the fate of cells in the developing Drosophila eye. Cell 64: 1069-1081.

Batterham, P., J.R. Crew, A.M. Sokac, J.R. Andrews, G.M.F. Pas- quini, G.A. Davies, R. Stocker, and J.A. Pollock. 1995. Genetic analysis of the lozenge gene complex in Drosophila melanogaster: Adult visual system phenotypes. I. Neurogenet. (in press).

Begemann, G., A.M. Michon, L.v.d. Voorn, R. Wepf, and M. Mlodzik. 1995. The Drosophila orphan nuclear receptor Seven-up requires the Ras pathway for its function in photoreceptor determination. Development 121: 225-235.

Blochlinger, K., L.Y. Jan, and Y.N. Jan. 1993. Postembryonic patterns of expression of cut, a locus regulating sensory organ identity in Drosophila. Development 117: 441-450.

Bunner, D., K. Ducker, N. Oellers, E. Hafen, H. Scholz, and C. Klambt. 1994. The ETS domain protein Pointed-P2 is a target of MAP kinase in the Sevenless signal transduction pathway. Nature 370: 386-389.

Capovilla, M., E.D. Eldon, and V. Pirrotta. 1992. The giant gene of Drosophila encodes a b-ZIP DNA-binding protein that regulates the expression of other segmentation gap genes. Development 114: 99-112.

Coyle-Thompson, C.A. and U. Baneriee. 1993. The strawberry notch gene functions with Notch in common developmental pathways. Development 119: 377-395.

Dickson, B., F. Sprenger, and E. Hafen. 1992. Prepattern in the developing Drosophila eye revealed by an activated torsosevenless chimeric receptor. Genes \& Dev. 6: 2327-2339.

Falb, D. and T. Maniatis. 1992. Drosophila transcriptional repressor protein that binds specifically to negative control elements in fat body enhancers. Mol. Cell. Biol. 12: 40934103.

Fischer-Vize, J.A., G.M. Rubin, and R. Lehmann. 1992. The fat facets gene is required for Drosophila eye and embryo development. Development 116: 985-1000.

Fortini, M.E., M.A. Simon, and G.M. Rubin. 1992. Signalling by the sevenless protein tyrosine kinase is mimicked by Ras 1 activation. Nature 355: 559-561.

Greenwald, I. and G.M. Rubin. 1992. Making a difference: The role of cell-cell interactions in establishing separate identities for equivalent cells. Cell 68: 271-281.

Gupta, B.P. and V. Rodrigues. 1995. Distinct mechanisms of action of the lozenge locus in Drosophila eye and antennal development are suggested by the analysis of dominant enhancers. I. Neurogenet. 10: 137-151.

Han, K. and J.L. Manley. 1993. Transcriptional repression by the Drosophila even-skipped protein: Definition of a minimal repression domain. Genes \& Dev. 7: 491-503.

Hay, B.A., T. Wolff, and G.M. Rubin. 1994. Expression of baculovirus P35 prevents cell death in Drosophila. Development 120: 2121-2129.

Heberlein, U. and K. Moses. 1995. Mechanisms of Drosophila retinal morphogenesis: The virtues of being progressive. Cell 81: 987-990

Higashiiima, S., T. Kojima, T. Michiue, S. Ishimaru, Y. Emori, and K. Saigo. 1992. Dual Bar homeo box genes of Drosophila required in two photoreceptor cells, $\mathrm{Rl}$ and $\mathrm{R} 6$, and primary pigment cells for normal eye development. Genes \& Dev. 6: $50-60$.

Hiromi, Y., M. Mlodzik, S.R. West, G.M. Rubin, and C.S. Goodman. 1993. Ectopic expression of seven-up causes cell fate changes during ommatidial assembly. Development 118: 1123-1135.

Jarman A.P., E.H. Grell, L. Ackerman, L.Y. Jan, and Y.N. Jan. 1994. Atonal is the proneural gene for Drosophila photoreceptors. Nature 369: 398-400.

Kagoshima, H., K. Shigesada, M. Satake, Y. Ito, H. Miyoshi, M. Ohki, M. Pepling, and J.P. Gergen. 1993. The Runt domain identifies a new family of heteromeric transcriptional regu- 
lators. Trends Genet. 9: 338-341.

Kania, M.A., A.S. Bonner, J.B. Duffy, and J.P. Gergen. 1990. The Drosophila segmentation gene runt encodes a novel nuclear regulatory protein that is also expressed in the developing nervous system. Genes \& Dev. 4: 1701-1713.

Krämer, H., R.L. Cagan, and S.L. Zipursky. 1991. Interaction of bride of sevenless membrane-bound ligand and the sevenless tyrosine-kinase receptor. Nature 352: 207-212.

Kramer, S., S.R. West, and Y. Hiromi. 1995. Cell fate control in the Drosophila retina by the orphan receptor seven-up: Its role in the decisions mediated by the ras signaling pathway. Development 121: 1361-1372.

Lindsley, D.L. and G.G. Zimm. 1992. The genome of Drosophila melanogaster, pp. 428-431. Academic Press, San Diego, CA.

Mlodzik, M., Y. Hiromi, U. Weber, C.S. Goodman, and G.M. Rubin. 1990. The Drosophila seven-up gene, a member of the steroid receptor gene superfamily, controls photoreceptor cell fates. Cell 60: 211-224.

Nucifora, G. and J.D. Rowley. 1995. AML1 and the 8;21 and $3 ; 21$ translocations in acute and chronic myeloid leukemia. Blood 86: 1-14

Ochman, H., A.S. Gerber, and D.L. Hartl. 1988. Genetic applications of an inverse polymerase chain reaction. Genetics 120: $621-623$.

Ogawa, E., M. Maruyama, H. Kagoshima, M. Inuzuka, J. Lu, M. Satake, K. Shigesada, and Y. Ito. 1993a. PEBP2/PEA2 represents a family of transcription factors homologous to the products of the Drosophila runt gene and the human AML1 gene. Proc. Natl. Acad. Sci. 90: 6859-6863.

Ogawa, E., M. Inuzuka, M. Maruyama, M. Satake, M. NaitoFujimoto, Y. Ito, and K. Shigesada. 1993b. Molecular cloning and characterization of PEBP2 $\beta$, the heterodimeric partner of a novel Drosophila runt-related DNA binding protein PEBP2 alpha. Virology 194: 314-331

Okuda, T., J. Deursen, S.W. Hiebert, G. Grosveld, and J.R. Downing. 1996. AML1, the target of multiple chromosomal translocations in human leukemia, is essential for normal fetal liver hematopoiesis. Cell 84: 321-330.

Ready, D.F., T.E. Hanson, and S. Benzer. 1976. Development of the Drosophila retina, a neurocrystalline lattice. Dev. Biol. 53: 217-240.

Rebay, I. and G.M. Rubin. 1995. Yan functions as a general inhibitor of differentiation and is negatively regulated by activation of the Rasl/MAPK pathway. Cell 81: 857-866.

Rogge, R., P.J. Green, J. Urano, S. Horn-Saban, M. Mlodzik, B. Shilo, V. Hartenstein, and U. Baneriee. 1995. The role of yan in mediating the choice between cell division and differentiation. Development 121: 3947-3958.

Rubin, G.M. and A.C. Spradling. 1982. Genetic transformation of Drosophila with transposable element vectors. Science 218: 348-353.

Satake, M., M. Inuzuka, K. Shigesada, T. Oikawa, and Y. Ito. 1992. Differential expression of subspecies of polyomavirus and murine leukemia virus enhancer core binding protein, PEBP2, in various hemopoietic cells. Ipn. I. Cancer Res 83: $714-722$

Simon, M.A., D.D. Bowtell, G.S. Dodson, T.R. Laverty, and G.M. Rubin. 1991. Ras1 and a putative guanine nucleotide exchange factor perform crucial steps in signaling by the sevenless protein tyrosine kinase. Cell 67: 701-716.

Takahasi, A., M. Satake, Y. Yamaguchi-Iwai, S-C. Bae, J. Lu, M. Maruyama, Y.W. Zhang, H. Oka, N. Arai, K. Arai, and Y. Ito. 1995. Positive and negative regulation of granulocyte-macrophage colony-stimulating factor promoter activity by AML1-related transcription factor, PEBP2. Blood 86: 607-
616.

Therrien, M., H.C. Chang, N.M. Solomon, F.D. Karim, D.A. Wassarman, and G.M. Rubin. 1995. KSR, a novel protein kinase required for RAS signal transduction. Cell 83: 879_ 888.

Tomlinson, A. and D.F. Ready. 1987a. Cell fate in the Drosophila ommatidium. Dev. Biol. 123: 264-275.

. 1987b. Neural differentiation in the Drosophila ommatidium. Dev. Biol. 120: 366-376.

Tomlinson, A., D.D.L. Bowtell, E. Hafen, and G.M. Rubin. 1987. Localization of the sevenless protein, a putative receptor for positional information in the eye imaginal disc of Drosophila. Cell 51: 143-150.

Tomlinson A., B.E. Kimmel, and G.M. Rubin. 1988. rough, a Drosophila homeobox gene required in photoreceptors R2 and $\mathrm{R} 5$ for inductive interactions in the developing eye. Cell 55: 771-784

Tsai, C. and J.P. Gergen. 1994. Gap gene properties of the pairrule gene runt during Drosophila segmentation. Development 120: 1671-1683.

Zipursky, S.L. and G.M. Rubin. 1994. Determination of neuronal cell fate: Lessons from the R7 neuron of Drosophila. Annu. Rev. Neurosci. 17: 373-397. 


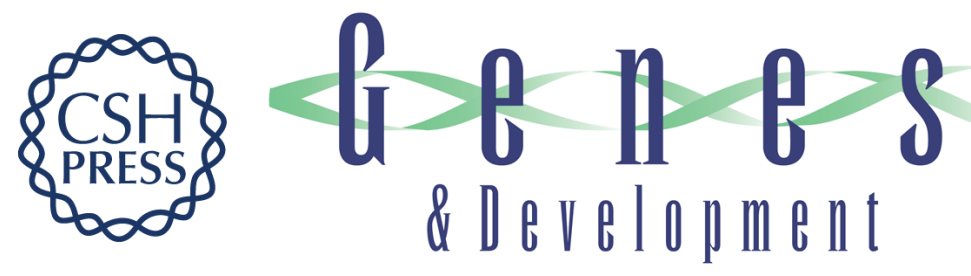

\section{Patterning of cells in the Drosophila eye by Lozenge, which shares homologous domains with AML1.}

A Daga, C A Karlovich, K Dumstrei, et al.

Genes Dev. 1996, 10:

Access the most recent version at doi:10.1101/gad.10.10.1194

References This article cites 44 articles, 21 of which can be accessed free at:

http://genesdev.cshlp.org/content/10/10/1194.full.html\#ref-list-1

License

Email Alerting

Service

Receive free email alerts when new articles cite this article - sign up in the box at the top right corner of the article or click here.

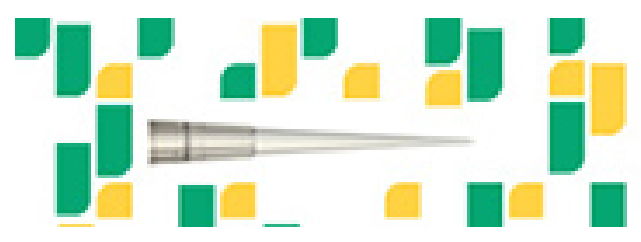

Focused on your science. 